\title{
REÚSO DE ÁGUA PARA O DESENVOLVIMENTO SUSTENTÁVEL: ASPECTOS DE REGULAMENTAÇÃO NO BRASIL E EM PORTUGAL
}

\author{
WATER REUSE FOR SUSTAINABLE DEVELOPMENT: REGULATORY ASPECTS IN BRAZIL
} AND PORTUGAL

\author{
Ana Silvia Pereira Santos ${ }^{a}$, José Manuel Pereira Vieira ${ }^{b}$

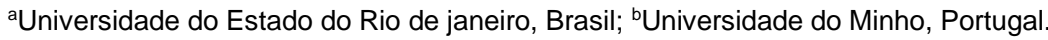 \\ e-mail: ana.pereira@uerj.br, jvieira@civil.uminho.pt
}

Submissão: 21 de abril de 2020

Aceitação: 14 de julho de 2020

\section{Resumo}

No presente artigo, apresenta-se uma análise comparativa do enquadramento regulatório de reúso de água do Brasil e de Portugal, inserido nos seus cenários de gestão de saneamento ambiental e recursos hídricos. Verifica-se que os índices de atendimento em serviços de água e esgotos são bastante distintos nos dois países, sendo semelhantes, no entanto, as respetivas taxas de reúso de água em relação ao esgoto total tratado (1,5\% no Brasil e 1,2\% em Portugal). A água de reuso vem se tornando uma importante fonte alternativa de aumento da disponibilidade hídrica para o desenvolvimento sustentável. Apesar dos aspectos de regulamentação de ambos os países apresentarem instrumentos de gestão similares, o Brasil tende a ser mais flexível em relação aos padrões de indicadores de contaminação fecal para o reúso de água para irrigação/rega de ambientes urbanos, combate a incêndio e lavagem de ruas. No caso de reúso para irrigação/rega de ambientes agrícolas e descarga de vaso sanitário, os padrões legais são igualmente restritivos. Padrões para usos na construção civil e na desobstrução de galerias de águas residuais somente constam no documento regulador brasileiro.

Palavras-chave: Contaminação fecal; Enquadramento legal; Rega / irrigação; Reúso agrícola; Reúso urbano.

\section{Abstract}

In this research work, a comparative analysis of the legal framework for water reuse in Brazil and Portugal within their scenarios of sanitation and water resources management is presented. It appears that the coverage in drinking water and sanitation services is quite different between the two countries. However, the respective rates of reuse of effluents in relation to the total wastewater treated are similar $(1.5 \%$ in Brazil and $1.2 \%$ in Portugal). Water reuse has become an important alternative source of increasing water availability for sustainable development. Despite the legal aspects of both countries presenting similar management instruments, Brazil tends to be more flexible in relation to the standards of fecal contamination indicators for the reuse of water for irrigation of urban environments, firefighting, and street washing. In the case of reuse for irrigation of agricultural environments and flushing the toilet, legal standards are equally restrictive. Standards for use in civil construction and clearing wastewater galleries are only included in the Brazilian regulatory document.

Keywords: Fecal contamination; Legal framework; Irrigation; Agricultural reuse; Urban reuse.

\section{Nota dos autores:}

Propositadamente, ao longo do texto, os autores adotaram indistintamente a ortografia usada nas variantes do idioma português do Brasil e de Portugal, com o objetivo de manter a integridade das versões oficiais dos diplomas legais respectivos e, adicionalmente, familiarizar os leitores com a linguagem técnica utilizada nos dois países. 


\section{INTRODUÇÃO}

O Brasil é o quinto maior país do mundo em extensão territorial, ocupando uma área de aproximadamente 8,5 milhões de $\mathrm{km}^{2}$ (IBGE, 2020a). Com uma população total de aproximadamente 221 milhões de habitantes, em 2020 (IBGE 2020b) e um IDH médio de 0,761, ocupa a $79^{a}$ posição no ranking de desenvolvimento humano publicado pela United Nations Development Program (UNPD, 2019). Portugal é um país com dimensões territoriais bastante inferiores, com ocupação de aproximadamente 0,09 milhões de $\mathrm{km}^{2}$ e uma população de aproximadamente 10 milhões de habitantes (PORDATA, 2020). Em relação ao desenvolvimento humano, ocupa a $40^{\mathrm{a}}$ posição com IDH médio de 0,850 (UNPD, 2019).

\section{1 Água e saneamento no Brasil}

No Brasil, adota-se "prestadoras de serviço" para designar as empresas que fornecem os serviços de abastecimento de água e de esgotamento sanitário à população. Segundo BRASIL (2019), essas podem ser de abrangência regional, microrregional, local de direito público, local de direito privado e local de empresa privada. Entretanto, a titularidade dos serviços é sempre do município, mesmo que temporariamente concedidos à outra entidade. Em relação aos serviços de esgotamento sanitário, a Agência Nacional de Águas (ANA) classifica a sua organização como sendo realizada de forma indireta (delegação da prestação dos serviços para autarquia municipal, companhia estadual ou concessionária privada) ou de forma direta (sem prestador de serviço institucionalizado). Em 2017, dos 5.570 municípios brasileiros, 2.982 (equivalente a $88,9 \%$ da população urbana do país) enquadravam-se no primeiro tipo e 2.588 (equivalente a pouco mais de $10 \%$ da população urbana brasileira), no segundo (ANA, 2017).

Em relação à prestação de serviços de abastecimento de água e esgotamento sanitário no Brasil, alguns dos dados mais relevantes para a pesquisa, são apresentados de forma resumida na Tabela 1.

Tabela 1: Cobertura em serviços de abastecimento de água e de esgotamento sanitário no Brasil (Referência: 2018)

\begin{tabular}{cllc}
\hline Serviço & \multicolumn{1}{c}{ Indicador } & Proporção (\%) \\
\hline \multirow{3}{*}{ Água } & Abastecimento de água (em relação à população total) & 83,6 \\
\cline { 2 - 3 } & Abastecimento de água (em relação à população urbana) & 92,8 \\
\cline { 2 - 3 } & Perdas de água na distribuição & 38,5 \\
\hline \multirow{3}{*}{ Esgoto } & Coleta de esgoto (em relação à população total) & 53,2 \\
\cline { 2 - 3 } & Coleta de esgoto (em relação à população urbana) & 60,9 \\
\cline { 2 - 3 } & Tratamento de esgoto (em relação ao esgoto total gerado) & 45,3 \\
\cline { 2 - 3 } & Tratamento de esgoto (em relação ao esgoto urbano coletado) & 74,5 \\
\hline Reúso & Efluente usado em relação ao esgoto tratado & $1,5^{(1)}$ \\
\hline
\end{tabular}

Fonte: BRASIL (2019); ANA (2017); ANA (2018).

Nota: (1) O valor foi calculado a partir da relação entre a vazão total de esgoto tratado $\left(132 \mathrm{~m}^{3} / \mathrm{s}\right)$ no ano de referência 2013 (ANA, 2017) e a vazão estimada de reuso (2 m³/s) no ano de referência 2017 (ANA, 2018).

Em relação à cobertura em serviços de abastecimento de água no ano de 2018, apesar de o índice em relação à população urbana ser relativamente alto, o mesmo distribuía-se de forma diversa ao longo dos vários estados: abaixo de $40 \%$ para o Amapá; abaixo de $60 \%$ para o Pará; abaixo de $80 \%$ para Acre, Rondônia, Maranhão, Ceará e Alagoas; e abaixo de $90 \%$ para Amazonas (Figura 1) (BRASIL, 2019). Realça-se que, em 2017, 60,9 milhões de brasileiros viviam em cidades com menor garantia de abastecimento de água, estimando-se que este número suba para 73,7 milhões de pessoas no horizonte de 2035 (ANA, 2019).

No caso da coleta de esgoto, o estado do Amapá apresenta-se em pior situação, juntamente com Rondônia e Pará, com índices de atendimento inferiores a $10 \%$. Os demais estados apresentam índices entre $10 \%$ e $70 \%$, exceto, Paraná, São Paulo, Minas Gerais e Distrito Federal, com índices acima de 70\% (Figura 2) (BRASIL, 2019). Essa realidade faz com que a maioria dos leitos em 
hospitais públicos do país sejam ocupados por doenças relacionadas com 0 saneamento ambiental inadequado (DRSAI) (FERREIRA et al., 2016; HELLER; COLOSIMO e ANTUNES, 2003).

No que respeita ao tratamento de esgotos, $O$

Figura 1: Índice médio de abastecimento de água por estado brasileiro. Referêcia: 2018

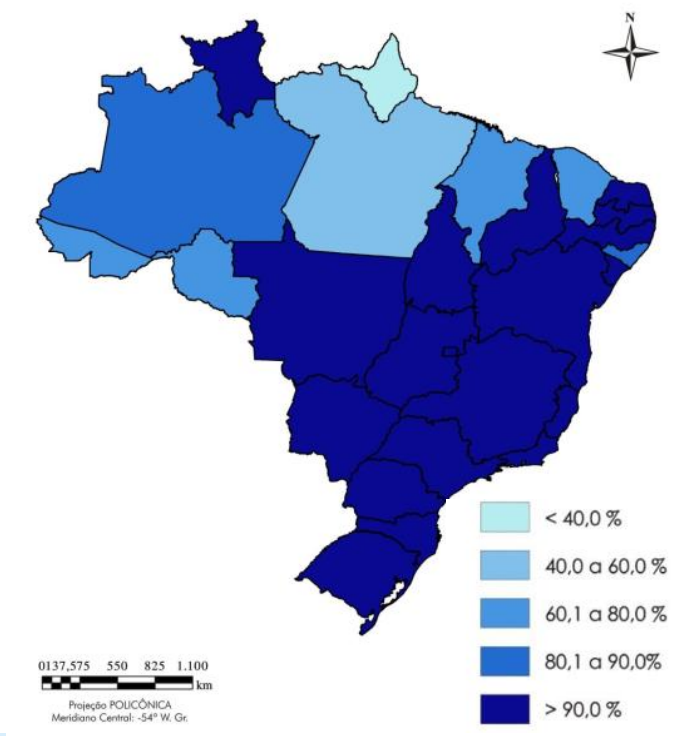

Fonte: BRASIL, 2019

E para agravar a situação, ANA (2017) indica que do total de 2.657 estações de tratamento de esgotos (ETE) com informações sobre desempenho, 53,7\% alcançam eficiência de remoção de matéria orgânica entre $60 \%$ e $80 \%$ e somente 970 unidades (36,5\%) são capazes de alcançar eficiências de remoção de matéria orgânica acima de $80 \%$. As demais, que representam quase $10 \%$ das unidades em operação, alcançam somente $60 \%$ de eficiência de remoção de matéria orgânica. Ainda, segundo BRASIL (2019), 1.531 municípios (30\%), nem sequer apresentam sistema de esgotamento sanitário e somente $10 \%$ da totalidade de municípios brasileiros tratam acima de $80 \%$ os seus esgotos gerados.

Considerando este cenário de afastamento da meta da universalização do esgotamento sanitário no Brasil, Araújo et al. (2019) evidenciam a necessidade de a atingir, não somente no sentido de minimizar a poluição dos meios hídricos e proteger a saúde pública, mas também em proporcionar efluentes tratados para a prática de reúso. É importante referir que esta prática vem-se destacando atualmente como uma importante baixo índice de atendimento observado é distribuído em 2.768 unidades em operação (2.657 com informações sobre desempenho) em 1.598 cidades, com população atendida estimada em 71,7 milhões de habitantes (ANA, 2017).

Figura 2: Índice médio de coleta de esgoto por estado brasileiro. Referêcia: 2018

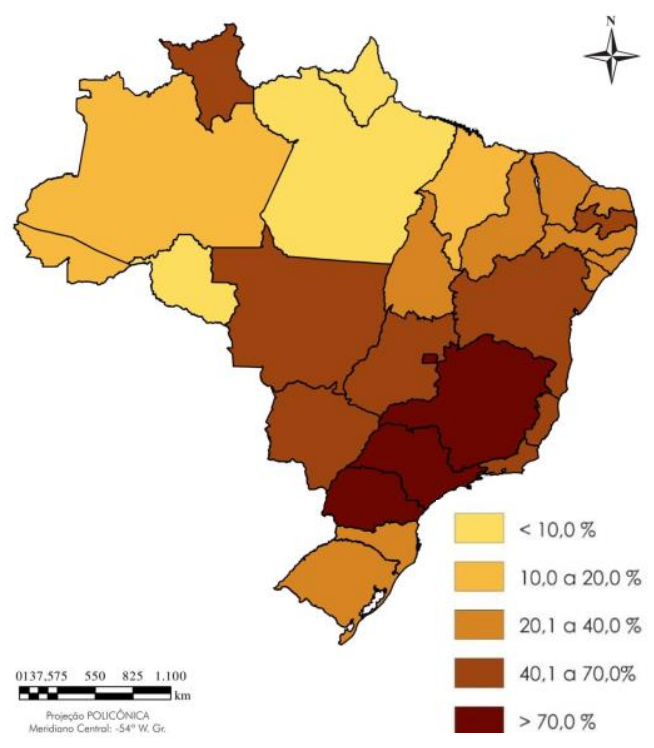

fonte alternativa para garantia da segurança hídrica em regiões com demanda superior à disponibilidade hídrica ou com a intensificação dos eventos de seca (MUKHERJEE e JENSEN, 2020; RICART e RICO, 2019).

Em 2018, foram registrados no Brasil 2.516 eventos de seca, afetando 43 milhões de pessoas, dentre as quais $90 \%$ se encontram na região Nordeste (ANA, 2019). Nesta situação, muitos municípios recorrem ao abastecimento emergencial por carros-pipa, após haverem esgotado soluções alternativas, nomeadamente perfuração emergencial de poços. No ano de 2018 , 718 municípios (2,41 milhões de habitantes) foram atendidos pela "Operação Carro-Pipa" do governo federal, com um custo total de 680 milhões de reais (ANA, 2019).

A perda de água nos sistemas de abastecimento público constitui um dos temas mais relevantes face aos cenários de escassez hídrica nos países em desenvolvimento, aliado aos altos custos de energia elétrica (BRASIL, 2019; MUTIKANGA; SHARMA e VAIRAVAMOORTHY, 2009; OVIEDO-OCAÑA et al., 2020; LOUREIRO et al., 2016). 
No Brasil, no ano de 2018, as perdas médias foram de quase $40 \%$ (Tabela 1 ). Na região Nordeste, onde se enfrentam os maiores desafios de escassez hídrica no país, as perdas alcançaram $46,0 \%$. Entretanto, a região Norte foi a que mais desperdiçou água nos sistemas de distribuição, com perdas de $55,5 \%$. A região Sudeste, de maior desenvolvimento socioeconômico no país, apresentou os mais baixos índices (34,4\%). Com referência às cidades, os destaques mais negativos são para os casos de Manaus, capital do Amazonas, com índice de perdas de 75,0\% e Porto Velho, capital de Rondônia com $77,7 \%$ (BRASIL, 2019).

Nesse evidente cenário de insegurança hídrica no país, esforços vêm sendo reunidos no sentido de se recorrer ao reúso de água como fonte alternativa para usos não potáveis. A ANA (2018) estimou que a vazão de reúso no Brasil em 2017 foi de cerca de $63 \times 10^{6} \mathrm{~m}^{3} /$ ano com um potencial de médio prazo (10 a 15 anos) para alcançar $315 \times 10^{6}$ a $473 \times 10^{6} \mathrm{~m}^{3} /$ ano. Os principais desafios para a generalização do reúso de água têm sido: objeção dos usuários, riscos associados ao reúso e regulamentação adequada (MUKHERJEE e JENSEN, 2020; RICART e RICO, 2019). Para a institucionalização de um instrumento como o reúso de água é fundamental a existência de um enquadramento legislativo que regule, direcione e dê segurança à sua aplicação.

Silva Jr. et al. (2019) mostraram que, embora - reúso de água possa ser ambiental e economicamente vantajoso, além de ser utilizado até mesmo como marketing ambiental, a prática nem sempre é divulgada pelas prestadoras de serviços de água e esgoto no Brasil. Segundo os autores, das 1.287 estações de tratamento de esgotos existentes na região Sudeste brasileira, somente quinze ( $1 \%)$ apresentam projetos institucionalizados e apenas nove $(0,7 \%)$ disponibilizam dados quantitativos a respeito da produção de água de reúso. Esse baixo índice pode ter várias causas, nomeadamente: a falta de incentivo, a falta de conhecimento dos possíveis clientes, o preconceito da população e a falta de amparo legal de maneira a dar garantias técnicas e legais tanto ao produtor como ao consumidor da água de reúso.

\section{2 Água e saneamento em Portugal}

Em Portugal, adota-se "entidade gestora" (EG) para designar as empresas prestadoras de serviços de abastecimento de água e de saneamento de águas residuais cujos modelos de gestão podem ser do tipo prestação direta do serviço, delegação do serviço em empresa ou ainda a sua concessão. São considerados multimunicipais os sistemas de titularidade estatal que sirvam pelo menos dois municípios e exijam a intervenção do Estado em função de razões de interesse nacional, e sistemas municipais todos os outros, relativamente aos quais cabe aos municípios, isoladamente ou em conjunto, através de associações de municípios, ou em parceria com o Estado, definir o modo de organização e gestão. No caso de sistemas de abastecimento de água e de saneamento de águas residuais, os operadores privados apenas podem assumir uma posição minoritária no capital das empresas concessionárias dos sistemas multimunicipais, restrição que não existe para as concessionárias de sistemas municipais (ERSAR, 2019).

Em relação à prestação de serviços de abastecimento de água e de saneamento de águas residuais em Portugal, alguns dos dados mais relevantes para a pesquisa, são apresentados de forma resumida na Tabela 2.

Tabela 2: Cobertura em serviços de abastecimento de água e de saneamento de águas residuais em Portugal (Referência: 2018)

\begin{tabular}{llc}
\hline \multicolumn{1}{c}{ Serviço } & \multicolumn{1}{c}{ Indicador } & Proporção (\%) \\
\hline Água & $\begin{array}{l}\text { Abastecimento de água (em relação à população total) } \\
\text { Perdas de água não faturada }\end{array}$ & $\begin{array}{c}96,0 \\
\text { a } 37,5^{(1)}\end{array}$ \\
\hline \multirow{2}{*}{ Águas residuais } & $\begin{array}{l}\text { Coleta de águas residuais (em relação à população } \\
\text { total) } \\
\text { Tratamento de águas residuais (em relação à } \\
\text { população total) }\end{array}$ & 85,0 \\
\hline Reúso & Efluente usado em relação a águas residuais tratadas & 84,0 \\
\hline
\end{tabular}

Fonte: ERSAR (2019).

Nota: (1) valores variando entre 4,7\% (condutas adutoras) e 37,5\% (redes de distribuição). 
De acordo com ERSAR (2019), o elevado índice de atendimento com abastecimento de água em Portugal considera 5.896 captações de água subterrânea e 295 captações de água superficial. Entretanto, $68,18 \%$ da água aduzida aos consumidores são provenientes de captações superficiais. Em relação ao número de unidades de tratamento de água, o país conta com 3.601 instalações em operação, das quais 269 são estações de tratamento de água completas e 3.332 são simplificadas, considerando principalmente a desinfecção.

Actualmente, praticamente a totalidade da população portuguesa é abastecida por sistemas de redes de distribuição pública. A sua grande maioria é constituída por sistemas de pequena dimensão (93\%), que representam apenas $19 \%$ do total da população servida (Figura 3).

Em termos de qualidade da água verifica-se que em 2018, tal como nos anos anteriores, foi atingido praticamente o pleno $(99,97 \%)$ em termos da percentagem de análises realizadas. Relativamente ao cumprimento dos valores paramétricos, verifica-se que a percentagem de água controlada e de boa qualidade é de $99,0 \%$. Na Figura 4 apresenta-se a evolução, desde 1993, do controlo de qualidade da água de consumo humano em Portugal (VIEIRA, 2018).

Em relação aos serviços de saneamento de águas residuais, Portugal continental conta com 4.370 instalações de tratamento, das quais 2.759 $(63 \%)$ correspondem a estações de tratamento de águas residuais (ETAR) e $1.611(37 \%)$ a fossas sépticas coletivas (ERSAR, 2019). O índice de coleta é muito próximo do índice de tratamento de águas residuais. Neste caso, observa-se que, para a grande maioria da população atendida, é adotado o sistema completo de saneamento, desde a coleta nas edificações até ao lançamento adequado no meio hídrico receptor.

Nas últimas duas décadas, os serviços de abastecimento de água e de saneamento de águas residuais em Portugal tem registado significativas evoluções, tanto em modelos de gestão como em metodologias de controlo de qualidade que, beneficiando de instrumentos de planeamento associados a planos de investimento, atingiram excelentes indicadores de atendimento e de qualidade. A implementação dos Planos Estratégicos de Abastecimento de Água e de Saneamento de Águas Residuais, os PEAASAR I (2000-2006) e PEAASAR II (2007-2013), permitiu uma evolução na concretização de objectivos de universalização daqueles serviços, dotando o país das infraestruturas indispensáveis para a prestação destes serviços com qualidade.

É importante destacar que os altos índices de atendimento em relação ao abastecimento doméstico em Portugal, para além da infraestrutura e da gestão eficiente, são garantidos pela disponibilidade média de água, considerada suficiente para as necessidades dos diferentes usos (ERSAR, 2019). No entanto, há uma elevada assimetria regional e temporal da disponibilidade de água, tendo como consequência, a necessidade de criar reservas que permitam ultrapassar os períodos de escassez (SANTOS et al., 2019).

Assim, de forma a minimizar a pressão sobre as massas de água no país, a implantação de sistemas de produção de água para reutilização assume uma importância cada vez maior. Segundo ERSAR (2019), em Portugal continental, são poucos os sistemas que produzem água para reutilização, mas já representam $8,5 \times 10^{6} \mathrm{~m}^{3} / \mathrm{ano}$ (cerca de $1,2 \%$ do total da água residual tratada). Desse volume produzido de água para reutilização, $12 \%$ é exportado e $88 \%$ é destinada a uso próprio da EG.

Assim como no Brasil, o reúso de água faz parte do planeamento de recursos hídricos em Portugal. No PENSAAR 2020 (Plano Estratégico Nacional para o Setor de Abastecimento de Água e Saneamento de Águas Residuais), instrumento estratégico para o setor das águas em Portugal, para o período de 2014 a 2020, foram definidos cinco objetivos estratégicos (também designados por eixos) e 19 objetivos operacionais (OP). Assim, o reúso de água é abordado de maneira direta no Eixo 3 - Otimização e Gestão Eficiente dos Recursos, em seu OP 3.5 (valorização de reúso e subprodutos); e de maneira indireta no Eixo 5 Condições Básicas e Transversais, em seu OP 5.4 (alterações climáticas, desastres naturais, riscos, mitigação e adaptação). Na medida M.3.5.1 da OP 3.5, destacam-se ações de intervenção com vista ao aumento da utilização da água residual tratada, com viabilidade do ponto de vista técnicoeconômico e ambiental. Nesse sentido, a utilização de águas residuais tratadas para fins múltiplos é presentemente encarada como um eixo central da gestão sustentável dos recursos hídricos, não havendo, no entanto, uma prática generalizada de aproveitamento das águas residuais urbanas em Portugal, mesmo em contextos regionais de maior escassez hídrica (ERSAR, 2019). 
Figura 3: Dimensão dos sistemas de abastecimento de água em Portugal em 2016

Zonas de abastecimento ( $n^{\circ}$ )

População servida ( $10^{6}$ hab.)

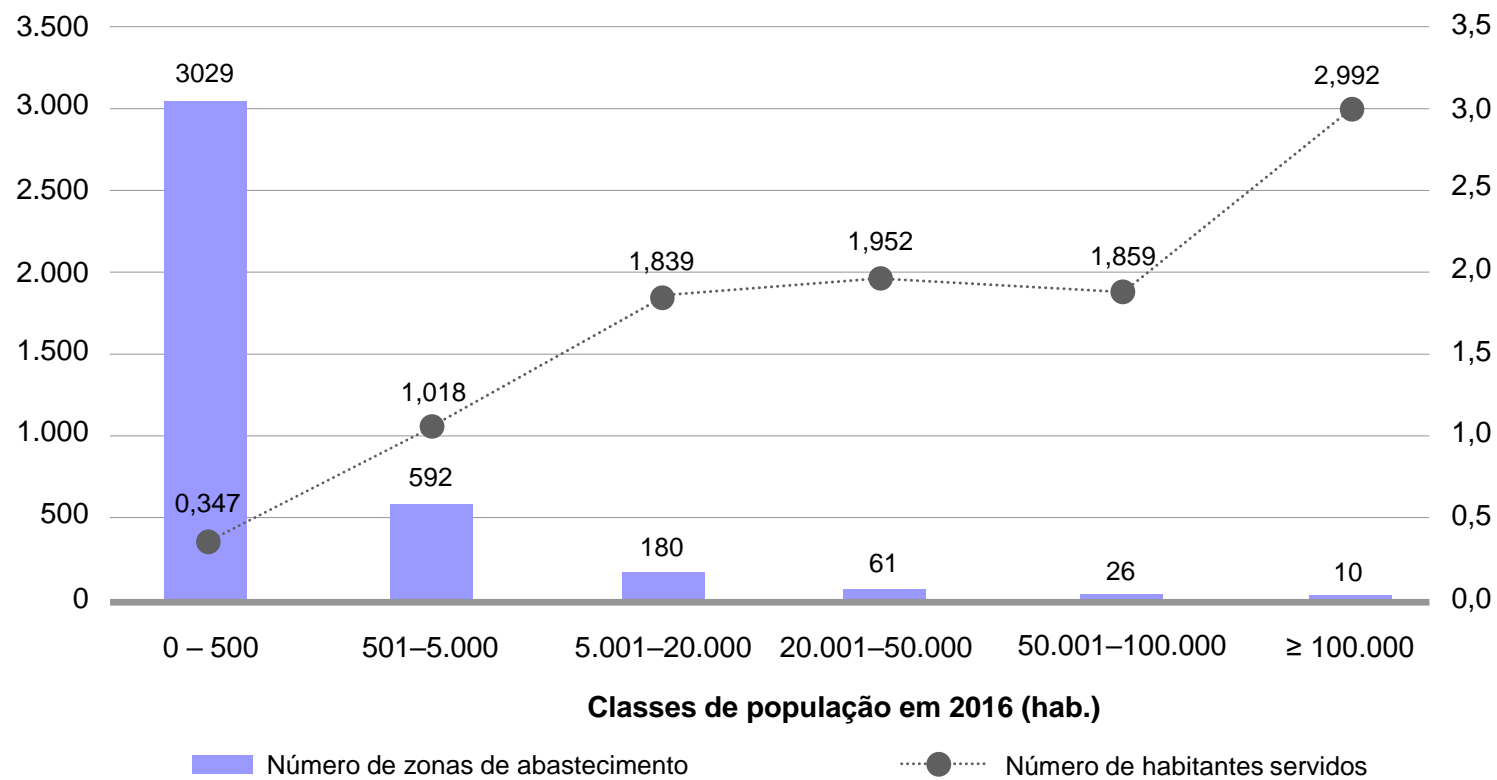

Fonte: Adaptado de Vieira (2011).

Figura 4: Controlo da qualidade de água de consumo humano. Portugal, 1993 - 2017

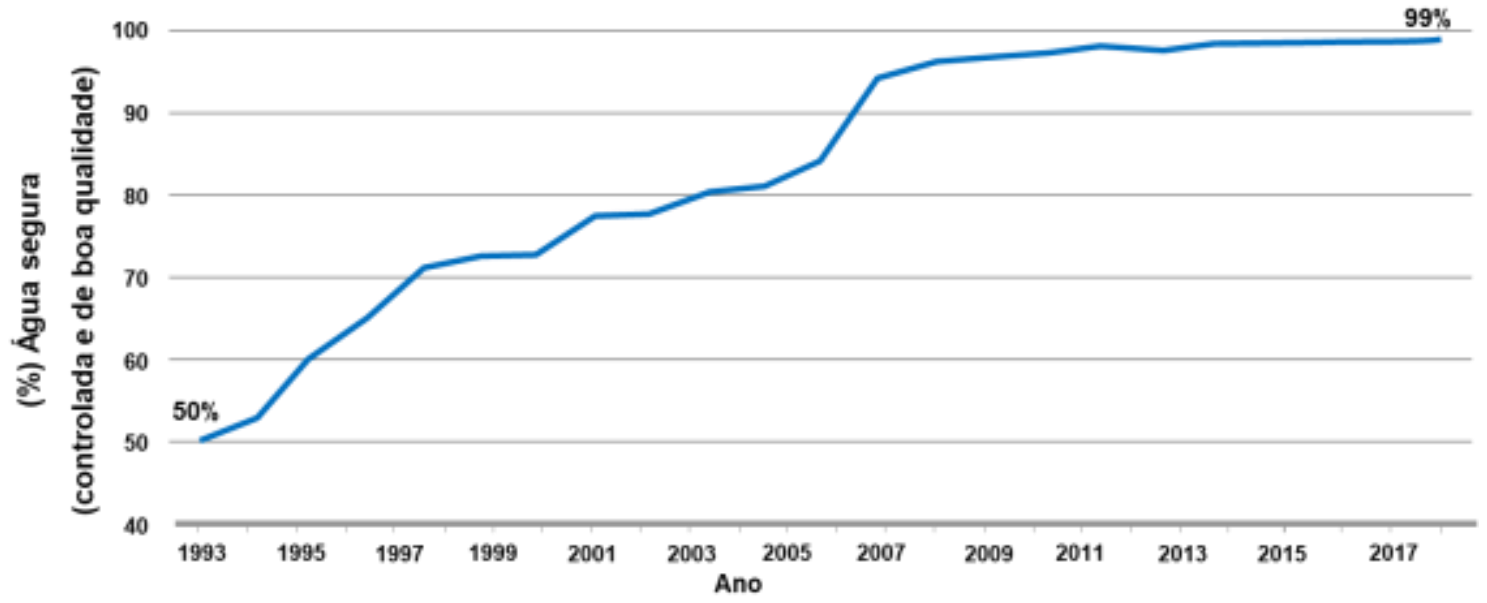

Fonte: Vieira (2018).

De acordo com o ERSAR (2019), a utilização de águas residuais tratadas deve basear-se, por um lado, no conhecimento científico e tecnológico do tratamento e, por outro, num adequado enquadramento institucional e de regulamentação. Segundo Ricart e Rico (2019), a Organização das Nações Unidas, através da sua Agenda 2030 para o Desenvolvimento Sustentável, vem incentivando a adoção de tecnologias de dessalinização e de reutilização de águas em todo o mundo, como um instrumento essencial para 0 alcance dos Objetivos de Desenvolvimento Sustentável. Por outro lado, é importante estabelecer um balanço entre os riscos associados à prática de reúso com regulamentação adequada e ações de combate à reação de aversão ou de repulsa que influencia diretamente a aceitabilidade de produtos relacionados com a água de reúso.

\subsection{Enquadramento de eventos excepcionais e alterações climáticas}

A ocorrência cada vez mais frequente de eventos extremos (secas e inundações) e os 
impactos de alterações climáticas constituem fenómenos que podem tornar mais vulneráveis os sistemas de abastecimento de água. De facto, a relevância sanitária desta vulnerabilidade pode traduzir-se em aspectos qualitativos e quantitativos, nomeadamente: (i) alterações na qualidade química de águas subterrâneas devido, por exemplo, a sobre-exploração de aquíferos, contaminação por nitrato ou compostos orgânicos por actividades agrícolas, intrusão salina por elevação do nível da água do mar; (ii) ruptura na continuidade de fornecimento de água ou dificuldade em garantir níveis de atendimento por insuficiências de disponibilidade de água nas origens, devido a elevação da temperatura atmosférica e consequente aumento da procura de água; (iii) efeitos negativos na infra-estrutura devido a eventos de seca e inundações, que podem colocar sérios riscos de contaminação química e microbiológica, para além de criar insegurança quanto à possibilidade de utilização de fontes de captação alternativas (VIEIRA, 2018).

O reúso de água é um fenómeno de importância e interesse cada vez mais crescente a nível internacional. No entanto, um longo caminho há ainda a percorrer para captar a adesão das populações para uma utilização mais generalizada de efluentes tratados. Neste contexto, assume papel determinante a estimação do nível de risco que Ihe está associado. Para isso, torna-se imperativo a aplicação de uma metodologia objetiva de identificação de perigos e avaliação dos riscos, baseada em escalas de "probabilidade de ocorrência" e de "severidade das consequências", de forma a limitar os elementos subjetivos do processo.

No presente trabalho apresenta-se uma análise comparada de aspetos legais relacionados com a prática de reúso da água no Brasil e em Portugal, numa perspectiva de sustentabilidade, em cenários de alterações climáticas e de crescente escassez hídrica. Para além da caracterização do estado da situação dos dois países relativamente a estes aspectos determinantes de saúde pública, espera-se que o presente trabalho possa trazer subsídio a uma melhor divulgação e conhecimento das políticas de gestão de recursos hídricos e saneamento ambiental em Portugal e no Brasil.

\section{METODOLOGIA}

Em relação aos instrumentos legais $e$ normativos que abordam a prática de reúso, adotaram-se, nesta pesquisa, somente documentos de abrangência nacional e que indicam padrões de qualidade para diferentes usos, não se considerando, aqui, os instrumentos legais que apenas regulam a prática de reúso. No caso do Brasil, analisaram-se as diretrizes indicadas pelo Programa de Desenvolvimento do Setor Água - INTERÁGUAS (INTERÁGUAS, 2018), que até o presente não foram convertidas em regulamento, tratando-se somente de um documento norteador. Em relação a Portugal, foi analisado o Decreto Lei $n^{\circ}$ 119/2019, recentemente publicado, que estabelece o regime jurídico de produção e utilização de água obtida a partir do tratamento de águas residuais (PORTUGAL, 2019). Neste contexto, analisou-se ainda o Guia para Reutilização de Águas - Usos Não Potáveis, publicado pela Agência Portuguesa do Ambiente (APA, 2019) que acompanha a referida Lei, com o objetivo de disseminar a prática de reúso no país de forma racional e segura.

Em 2018, o Brasil finalizou o Programa de Desenvolvimento do Setor Água (INTERÁGUAS) (INTERÁGUAS, 2018), financiado pelo Banco Mundial, envolvendo os Ministérios do Meio Ambiente, das Cidades e da Integração Nacional; os dois últimos passaram a formar o Ministério do Desenvolvimento Regional. O documento, que foi amplamente discutido em oficinas didáticas, em todas as regiões do país, de modo a abranger as peculiaridades regionais, teve por objetivo contribuir para o fortalecimento da capacidade de planejamento e gestão no setor água. Dentre as suas componentes, destaca-se aqui a relacionada com a proposta de arcabouço normativo e legal, para a prática de reúso de água no território nacional. A iniciativa contempla as diferentes opções de reúso: agrícola, urbano, industrial, ambiental e aquícola e propõe um conjunto de normas e procedimentos com o propósito de regulamentar a prática no país tanto no setor público como no setor privado (INTERÁGUAS, 2018). Conforme mencionado anteriormente, este documento não apresenta força legal, porém tratase do mais recente instrumento regulador e de gestão de reúso do país.

Em Portugal, em agosto de 2019, foi promulgado o instrumento legal no nível nacional, o Decreto Lei no. 119/2019 (PORTUGAL, 2019) e em outubro do mesmo ano, foi publicado o Guia para reutilização de água para usos não potáveis, no âmbito da Agência Portuguesa do Ambiente (APA). Este guia tem como objetivo permitir que a reutilização da água seja realizada de forma 
segura e adaptada a cada uso concreto e por isso suportada numa análise de custo-eficácia equilibrada e competitiva (APA, 2019). Esse quadro regulatório de Portugal, comtempla as seguintes opções de reúso: rega, urbano e industrial.

Diante dos distintos padrões de qualidade de água que envolvem as diferentes tipologias de reúso nos respectivos documentos estudados, optou-se por ressaltar no presente trabalho, somente os padrões de contaminação fecal por estarem diretamente relacionados à principal questão envolvida com a prática de reúso: saúde pública. O documento brasileiro refere-se à contaminação fecal a partir do parâmetro "Coliformes termotolerantes" e o documento português, a partir do parâmetro "Escherichia coli". Assim, em função dessa tênue diferença, a comparação foi feita de maneira indireta, de modo a não confrontar diretamente os valores estabelecidos pelos documentos.

O fluxograma referente à metodologia adotada para a análise dos dados pode ser observado na Figura 5, considerando os documentos reguladores dos dois países e suas respectivas tipologias de reúso. Ainda cabe destacar que a análise foi realizada em relação à rega/irrigação e aos usos urbanos, por se apresentarem comuns a ambos os países. $\mathrm{O}$ uso industrial, apesar de comum a ambos, apresenta abordagens distinta: no caso de Portugal, abordase o contato humano com a água em ambiente industrial; no caso do Brasil, a tipologia envolve, de fato, os usos industriais.

\section{RESULTADOS E DISCUSSÃO}

Inicialmente, estão apresentados de maneira resumida, os principais padrões de qualidade de água para as diferentes tipologias de reuso, adotados nos documentos reguladores de ambos os países. A Tabela 3 refere-se aos padrões adotados no Brasil, para todas as tipologias de reúso envolvidas em seu documento regulador. Para os padrões portugueses, nas Tabelas 4, 5 e 6 podem ser observados, os principais padrões de qualidade de água para as tipologias de reúso definidas como rega, urbano e industrial, respectivamente.

Figura 5: Fluxograma da metodologia adotada para a análise dos documentos reguladores para a reutilização de águas no Brasil e em Portugal

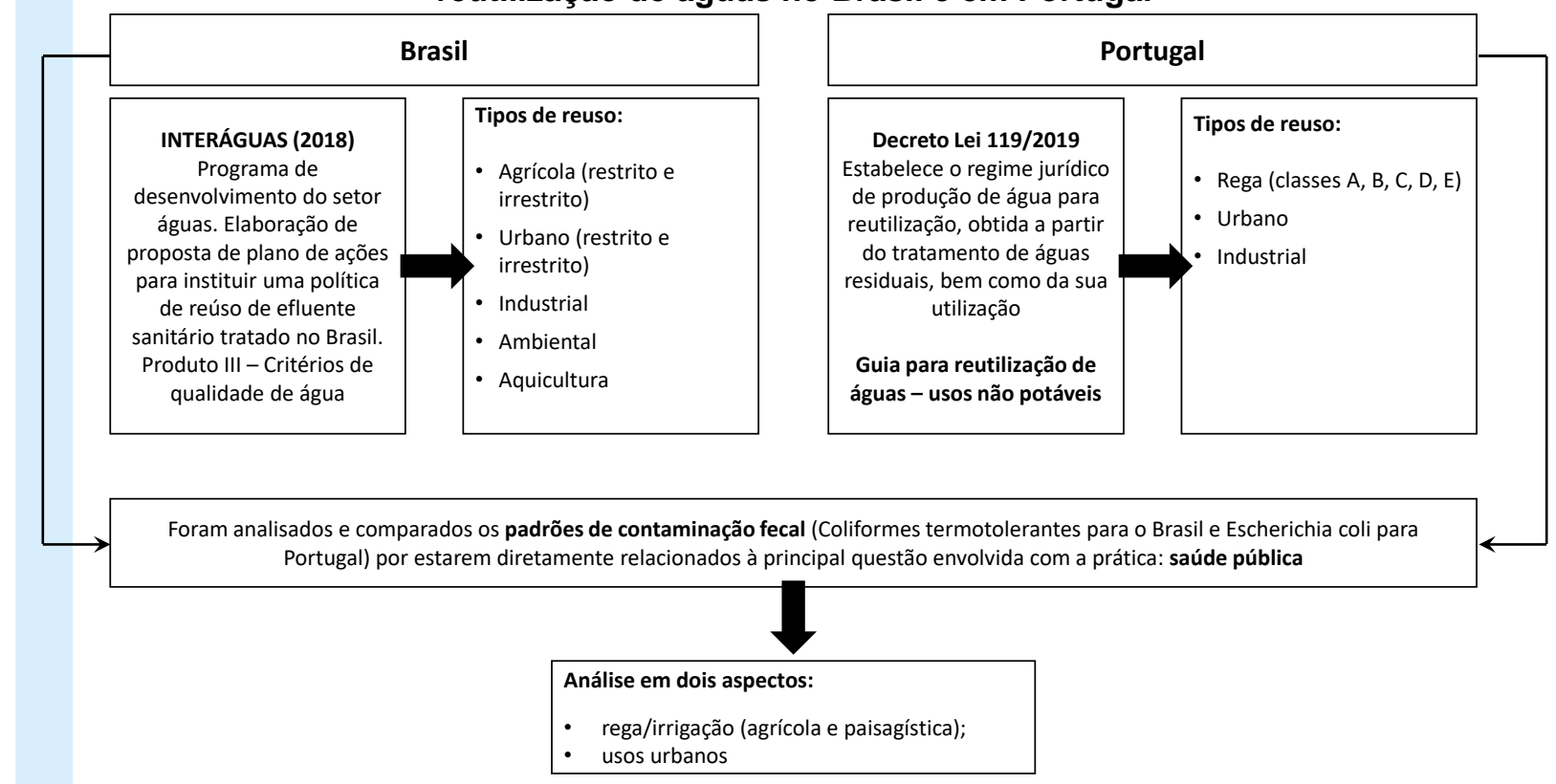


Tabela 3: Limites estabelecidos para parâmetros de qualidade de água relacionados ao reúso de água no Brasil

\begin{tabular}{|c|c|c|c|c|c|}
\hline Tipologia de reúso & $\begin{array}{c}\begin{array}{c}\text { Coliformes } \\
\text { termotolerantes }\end{array} \\
\mathrm{NMP} / 100 \mathrm{~mL}\end{array}$ & $\begin{array}{c}\begin{array}{c}\text { Ovos } \\
\text { Helmintos }\end{array} \\
\text { un/L }\end{array}$ & $\begin{array}{c}\text { Turbidez } \\
\text { NTU }\end{array}$ & $\begin{array}{l}\text { DBO } \\
\mathrm{mg} / \mathrm{L}\end{array}$ & $\begin{array}{c}\begin{array}{c}\text { Cloro } \\
\text { residual }\end{array} \\
\mathrm{mq} / \mathrm{L}\end{array}$ \\
\hline $\begin{array}{l}\text { Agrícola Restrito. Irrigação de } \\
\text { cultura de alimentos destinados ao } \\
\text { consumo humano sem } \\
\text { processamento prévio (plantas que } \\
\text { se desenvolvem distantes do nível } \\
\text { do solo); Irrigação de culturas de } \\
\text { alimentos que necessitam de } \\
\text { processamento antes de serem } \\
\text { consumidos e culturas não } \\
\text { destinadas ao consumo humano; } \\
\text { cultivo de florestas plantadas. }\end{array}$ & $10^{3}$ & 1 & - & 30 & 1,0 \\
\hline
\end{tabular}

Agrícola Irrestrito. Irrigação de cultura de alimentos destinados ao consumo humano sem processamento prévio (plantas que 10

$\begin{array}{lll}5 & 15 & 1,0\end{array}$
se desenvolvem rentes ao nível do solo).

Urbano Restrito. Irrigação paisagística e outros usos urbanos - em áreas restritas (sem contato público frequente e/ou com restrição de acesso).

\begin{tabular}{lccccc}
\hline $\begin{array}{l}\text { Urbano Irrestrito. Irrigação } \\
\text { paisagística e outros usos urbanos } \\
- \text { em áreas públicas }\end{array}$ & 10 & 1 & 5 & 15 & 1,0 \\
\hline $\begin{array}{l}\text { Industrial. Aplicação em vários } \\
\text { processos e atividades industriais }\end{array}$ & $10^{3}$ & - & - & - & - \\
\hline $\begin{array}{l}\text { Ambiental. Aplicação em lagoas } \\
\text { urbanas, manutenção de wetlands } \\
\begin{array}{l}\text { e aumento da disponibilidade } \\
\text { hídrica para fins ambientais. }\end{array}\end{array}$ & $10^{3}$ & $1^{(1)}$ & - & 60 & - \\
\hline $\begin{array}{l}\text { Aquicultura. Utilização para a criação } \\
\text { de peixe ou cultivo de vegetais } \\
\text { aquáticos. }\end{array}$ & $10^{3}$ & $1^{(1)}$ & - & 60 & - \\
\hline
\end{tabular}

Fonte: INTERÁGUAS (2018).

Legenda: DBO (Demanda Bioquímica de Oxigênio)

Nota: ${ }^{(1)}$ ausência de trematóides intestinais. 
Tabela 4: Limites estabelecidos para parâmetros de qualidade de água relacionados ao reúso de água em rega em Portugal

\begin{tabular}{lccccc}
\hline \multirow{2}{*}{ Classe de qualidade de rega } & E. Coli & $\begin{array}{c}\text { Ovos }{ }^{(1)} \\
\text { Helmintos }\end{array}$ & Turvação & CBO & SST \\
\cline { 2 - 6 } & UFC/100 $\mathbf{~ m L}$ & un/L & UTN & mg/L & mg/L \\
\hline $\begin{array}{l}\text { Classe A. Sem restrição de acesso (usos } \\
\text { urbanos e agrícolas): culturas }\end{array}$ & & & & & \\
$\begin{array}{l}\text { consumidas em cru em que a parte } \\
\text { consumível está em direto contato com a } \\
\text { água; jardins públicos sem restrição de } \\
\text { acesso; jardins privados. }\end{array}$ & 10 & - & 5 & 10 & 10 \\
\hline
\end{tabular}

Classe B. Com restrição de acesso (usos urbanos e agrícolas): culturas consumidas em cru, que crescem acima do solo, e em que a parte consumível não está em direto contato com a água; culturas agrícolas destinadas a processamento e de culturas agrícolas não destinadas ao consumo 100 $25 \quad 35$ humano, incluindo culturas destinadas ao consumo animal (produção de leite ou carne), exceto suínos; jardins com restrição de acesso, incluindo áreas de lazer e desportivas.

Classe C. Com restrição de acesso (usos agrícolas): culturas consumidas em cru, que crescem acima do solo, e em que a parte consumível não está em direto contato com a água; culturas agrícolas destinadas a processamento e culturas 1000 $1 \quad-\quad 25$ 35 agrícolas não destinadas ao consumo humano, incluindo culturas destinadas ao consumo animal (produção de leite ou carne), exceto suínos.

Classe D. Com restrição de acesso (usos agrícolas): produção de sementes, incluindo sementes para uso industrial ou 10.000 25 35 produção de energia.

Classe E (2). Com restrição de acesso (usos agrícolas): produção de sementes; rega de áreas de uso naturalmente restrito.

Fonte: Portugal (2019).

Legenda: CBO (Carência Bioquímica de Oxigênio); SST (sólidos em suspensão totais).

Notas: ${ }^{(1)}$ aplicável na rega de culturas agrícolas destinadas ao consumo animal; (2) Aplicável somente a sistemas descentralizados (que fazem reutilização para uso próprio).

Obs.: Os parâmetros Azoto Amoniacal (10mg/L), Azoto Total (15mg/L) e Fósforo Total (5mg/L) são facultativos podendo ser aplicáveis para minimização dos riscos de formação de biofilme e obstrução dos sistemas de rega; para proteção das culturas agrícolas, florestais e dos solos, há norma de qualidade referente aos metais Al, Be, Co, Fe, Li, Mn, Mo, Se, Va, Bo, além de fluoretos, SAR (razão de adsorção de sódio) e salinidade. 
Tabela 5: Limites estabelecidos para parâmetros de qualidade de água relacionados com o reúso de água em ambientes urbanos e paisagísticos em Portugal

\begin{tabular}{|c|c|c|c|c|c|c|}
\hline \multirow{2}{*}{$\begin{array}{l}\text { Tipo de uso } \\
\text { urbano }\end{array}$} & E. Coli & pH & Turvação & CBO & $\begin{array}{c}\text { Azoto } \\
\text { amoniacal }\end{array}$ & $\mathbf{P}_{\text {total }}$ \\
\hline & UFC/100 mL & - & UTN & $\mathrm{mg} / \mathrm{L}$ & $\mathrm{mgNH}_{4} / \mathrm{L}$ & $\mathrm{mg} / \mathrm{L}$ \\
\hline $\begin{array}{l}\text { Recreativo e } \\
\text { enquadramento } \\
\text { paisagístico }\end{array}$ & 10 & 6,0 a 9,0 & 5 & 25 & 5 & $2^{(3)}$ \\
\hline $\begin{array}{l}\text { Lavagem de } \\
\text { ruas (5) }\end{array}$ & - & 6,0 a 9,0 & - & 25 & - & - \\
\hline $\begin{array}{l}\text { Água de controle } \\
\text { a incêndios }{ }^{(1)}\end{array}$ & 10 & 6,0 a 9,0 & 5 & 25 & - & - \\
\hline $\begin{array}{l}\text { Água de } \\
\text { arrefecimento }\end{array}$ & 200 & 6,5 a $8,5^{(2)}$ & - & 25 & $5^{(6)}$ & - \\
\hline Autoclismos (1) & 10 & 6,0 a 9,0 & 5 & 25 & 10 & - \\
\hline $\begin{array}{l}\text { Lavagem de } \\
\text { veículos (4) (5) }\end{array}$ & 10 & 6,0 a 9,0 & 5 & - & - & - \\
\hline
\end{tabular}

Fonte: Portugal (2019).

Legenda: CBO (Carência Bioquímica de Oxigênio); Azoto (nitrogênio); P (fósforo)

Notas: ${ }^{(1)}$ características similares à "Rega Classe A" em função da consideração de máxima importância da possibilidade de ingestão (não intencional); ${ }^{(2)}$ possibilidade de crescimento microbiano com valores superiores ou inferiores ao intervalo proposto; (3) quando utilizado em locais sujeitos a eutrofização; ${ }^{(4)}$ poderão ser controlados alguns metais e compostos iónicos tais como ferro, manganês, cloretos, sulfatos, alcalinidade e sílica para minimização da ocorrência de calcificação ou corrosão; ${ }^{(5)}$ Características similares à "Rega Classe A" em função da consideração de máxima importância da possibilidade de ingestão (não intencional) em sistemas de lavagem manual a alta pressão; ${ }^{(6)}$ deve ser $\leq 1,0 \mathrm{mg} / \mathrm{L}$ em presença de cobre.

Obs.: No caso do uso destinado ao "suporte de ecossistemas", devem-se determinar caso a caso os parâmetros CBO, pH, turvação, azoto amoniacal e fósforo total, em função do estado ecológico e respectivos parâmetros de suporte; o parâmetro $E$. Coli não se aplica neste caso.

Tabela 6: Limites estabelecidos para parâmetros de qualidade de água relacionados com o reúso de água industrial em Portugal

\begin{tabular}{lcc}
\hline \multicolumn{1}{c}{ Classe de qualidade } & Turvação & E. Coli \\
\cline { 2 - 3 } & UTN & UFC/100mL \\
\hline $\begin{array}{l}\text { Em circuitos com risco direto de } \\
\text { ingestão (incluindo ingestão acidental) }\end{array}$ & 5 & 10 \\
\hline $\begin{array}{l}\text { Em circuitos com risco de contato } \\
\text { dérmico }\end{array}$ & 5 & 1000 \\
\hline Fonte: Portugal (2019)
\end{tabular}

Fonte: Portugal (2019).

Posteriormente, a discussão é apresentada de maneira comparativa em relação somente aos parâmetros de contaminação fecal, nos âmbitos da rega/irrigação (agrícola e paisagística) (item 3.1) e dos usos urbanos (item 3.2), conforme critérios descritos na metodologia. Em Portugal, dentro dos padrões de rega, são assumidos critérios para agricultura, jardins públicos ou privados, campos desportivos e ambientes urbanos. No Brasil, a irrigação em ambientes urbanos é assumida somente inserida no padrão de uso urbano. Assim, o item 3.1 foi definido como rega/irrigação agrícola e paisagística e o item 3.2 foi definido para os demais usos urbanos.

Anteriormente à análise comparativa, é relevante destacar três aspectos:

- Os documentos reguladores do Brasil e de Portugal abordam a necessidade de um seguro contra incidentes, além de apresentarem planos de monitoramento e 
mecanismos de licenciamento, em diferentes etapas e com graus de aplicação distintos, levando em consideração as particularidades de cada país, já amplamente discutidas. Ambos, ainda apresentam informações sobre tecnologias apropriadas para cada tipologia de reúso; e o de Portugal, aborda aspectos de avaliação do risco.

- A legislação de Portugal ainda envolve um importante instrumento de gestão, que se trata da imposição de uma caução no processo de licenciamento, e uma identidade visual para "Água para Reutilização - ApR". A caução tem 0 objetivo de garantir 0 pagamento de indemnizações por eventuais danos causados por erros ou omissões de projeto ou por incumprimento das disposições legais. A identidade visual (ApR) a ser utilizada de diferentes formas, tamanhos e aspectos em projetos de reúso pelo país, tem o objetivo de sinalizar e criar maior aderência com empresas, órgãos fiscalizadores e público em geral.

- Em qualquer dos dois enquadramentos reguladores analisados não é tida em devida conta a consideração de metodologias e planejamento para o abrandamento do fator "nojo" (yuck em inglês). Trata-se da rejeição dos usuários ao se abordar projetos de reúso de água, que naturalmente são associados à característica organoléptica de odor, apesar de não dever apresentá-la na maior parte dos casos. Projetos de reúso bem avaliados e bem estruturados podem não sair do papel em função da negligência relacionada aos aspectos de confiança do usuário (HARRISLOVETT et al., 2015). Os projetos de reúso devem adotar uma abordagem estratégica, antes e durante a instalação e operação à escala real, considerando operação de escala piloto, coleta de dados e informações, comunicação transparente com o público e com outras agências governamentais e gerenciamento de risco (MUKHERJEE e JENSEN, 2020).

$\mathrm{Na}$ discussão que se segue, conforme já mencionado, são comparados os valores normativos referentes aos parâmetros de contaminação fecal (Coliformes termotolerantes e E. Colit) adotados pelos dois países: 3.1 irrigação/rega (agrícola e paisagística); e 3.2 usos urbanos.

\subsection{Padrões de reúso para rega/irrigação}

Na Tabela 7 estão apresentados os padrões de contaminação fecal (Coliformes termotolerantes no Brasil e Escherichia coli em Portugal) para usos na irrigação/rega.

\section{Rega/Irrigação agrícola}

Os padrões para indicadores de contaminação fecal em ambos os países e para os diferentes tipos de uso em rega/irrigação na agricultura são igualmente restritivos e variam entre 10 e 1.000 organismos $/ 100 \mathrm{~mL}$, apesar de adotaram parâmetros distintos. A justificação para esta preocupação restritiva relaciona-se com a própria cultura irrigada, com o solo, com os trabalhadores e com os usuários.

Muitas pesquisas conduzidas com irrigação de diferentes culturas com efluentes sanitários tratados afirmam que, eventualmente, há contaminação das primeiras camadas do solo e somente da parte exterior do vegetal (SANTOS et al., 2006; ROCHA; PIMENTEL e ZAGO, 2003; ALLAHHAM; EL-ASSI e FAYYAD, 2003; PEDRERO et al., 2010). Em relação aos trabalhadores e usuários, medidas de segurança eficazes diminuem o risco de contaminação (CHHIPISHRESTHA; HEWAGE e SADIQ, 2017; TSAGARAKIS et al., 2013).

Assim, observa-se que de acordo com a exposição ao risco de contaminação, os padrões são adotados de forma a minimizá-lo. Porém, os padrões numéricos aplicados a uma lista de contaminantes químicos e microbiológicos não garantem por si só o nível de segurança requerido (CHHIPI-SHRESTHA; HEWAGE e SADIQ, 2017; SALGOT et al., 2006; ROCK et al., 2019; BEAUDEQUIN et al., 2015). Segundo APA (2019), a abordagem deve ser dirigida a cada projeto (fitfor-purpose), com um plano de gestão de risco que envolva medidas de controle, barreiras e planos de monitoramento.

\section{Rega/Irrigação em ambientes urbanos}

Nos casos de rega/irrigação em ambientes urbanos, o documento regulador do Brasil tende a ser mais flexível, permitindo irrigação com densidade de microrganismos maior do que a estabelecida pelo documento legal de Portugal, para além da utilização de diferentes microrganismos indicadores. 
Apesar de ter poucos projetos em andamento, Portugal já adquiriu uma experiência relevante para a prática de reúso de água, o que permite adotar níveis de exigência de qualidade mais elevados. De acordo com Sato et al. (2013), no sul da Europa, o efluente tratado recuperado é usado predominantemente para a irrigação $(44 \%$ dos projetos) e projetos urbanos e ambientais $(37 \%$ dos projetos).
O Brasil desenvolveu-se em torno de uma cultura de abundância de água que começou a ser questionada recentemente. $\mathrm{Na}$ realidade, somente nos últimos anos se tomou consciência das consequências da escassez hídrica, salientandose o fato de, no ano de 2013, parte significativa do país ter iniciado o seu mais longo processo de seca severa (CUNHA et al., 2015).

Tabela 7: Padrões de contaminação fecal para o reúso de água para rega/irrigação (agrícola e/ou urbano) no Brasil e em Portugal

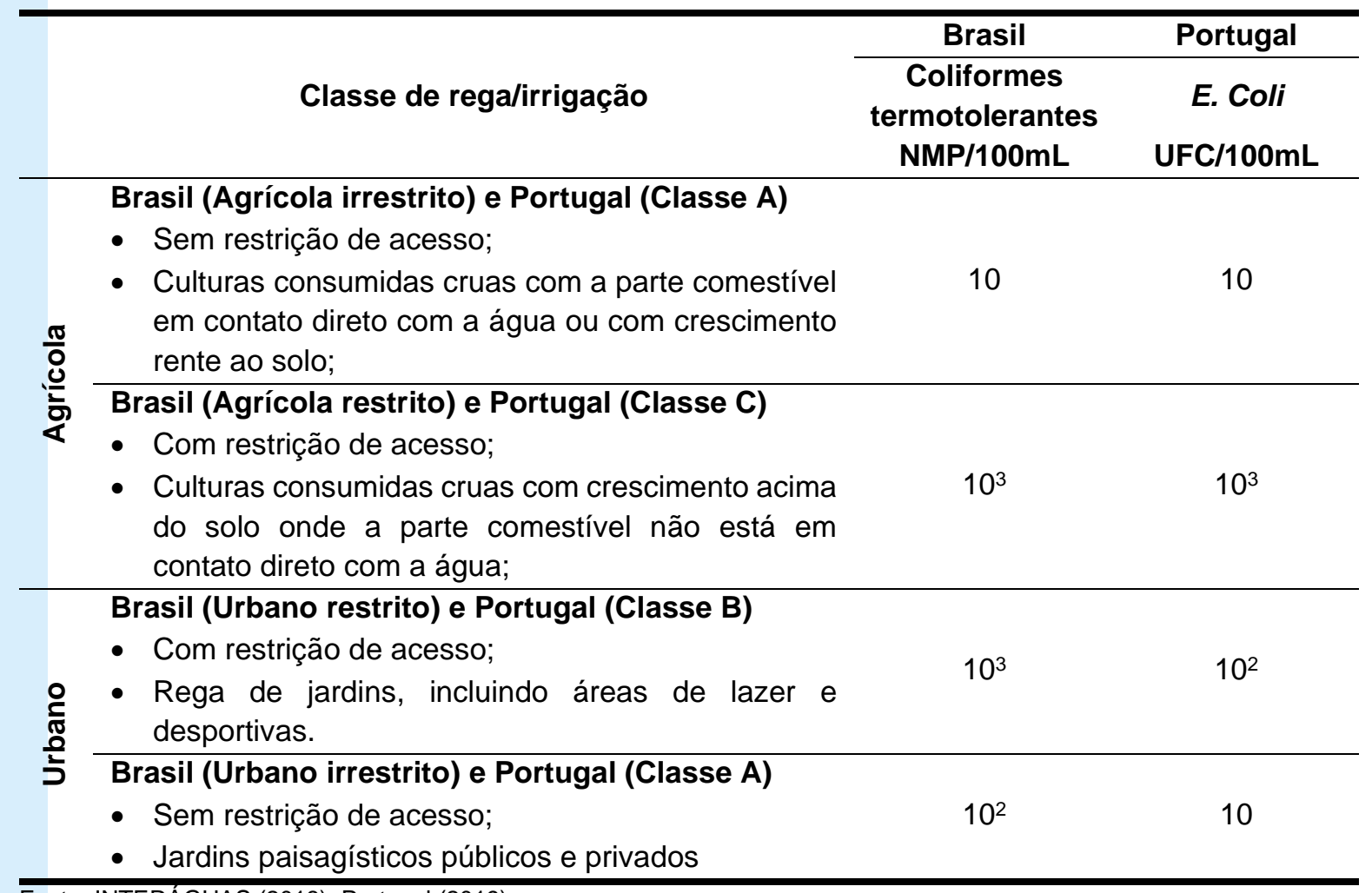

Fonte: INTERAGUAS (2018); Portugal (2019).

Apesar de não ser possível a comparação direta entre os padrões de contaminação fecal dos dois países, observa-se que o documento brasileiro é ligeiramente mais flexível do que o de Portugal. Esse fato pode constituir um incentivo para uma utilização generalizada de água de reúso na irrigação no Brasil. A experiência adquirida pode, no futuro, proporcionar uma evolução no sentido de uma maior exigência de qualidade da água de reuso e, consequentemente, nos padrões estabelecidos. Diferentes qualidades de efluente são alcançadas em função do nível de tratamento adotado (primário, secundário e terciário). Conforme já mencionado, segundo ANA (2017),
$10 \%$ das ETEs em operação no Brasil se enquadram no nível primário com eficiência de remoção de matéria orgânica de até $60 \%$; nos níveis primário avançado e secundário, se enquadram $53,7 \%$ com eficiência de remoção de matéria orgânica entre $60 \%$ e $80 \%$; e $36,5 \%$ no nível secundário com eficiências de remoção de matéria orgânica acima de $80 \%$. Dessa última categoria, somente $7 \%$ apresentam algum tipo de desinfecção.

Para a produção de água de reúso para irrigação, Tsagarakis et al. (2013) afirmam, de maneira simplificada, que: o tratamento primário remove $30-40 \%$ de matéria orgânica e 
patogênicos; o secundário com desinfecção, 95\%; e o terciário com desinfecção, $99 \%$ de carga orgânica e nenhum organismo patogênico. Nesse sentido, de acordo com Tzanakakis et al. (2011), o tratamento primário pode ser usado para irrigação controlada de florestas e parques, desde que sejam tomadas medidas de precaução e segurança adequadas. O secundário é apropriado para irrigação de árvores cujo fruto não tem contato direto com a água e em geral são processados antes de serem consumidos. Por fim, o terciário é apropriado para todos os tipos de culturas consumidas pelos seres humanos. Em Israel, 97\% das estações de tratamento de esgotos recebem tratamento terciário e esse efluente pode ser usado para irrigação de todos os tipos de cultura, sem restrição (MARIN, TAL e YERES, 2017).

Nos documentos reguladores do Brasil e de
Portugal indicam-se fluxogramas de tratamento de efluentes para alcance dos seus padrões definidos. No caso de Portugal, para todas as classes de rega, indica-se o nível de tratamento mais avançado do que secundário, sugerindo a desinfecção (PORTGUAL, 2019). No Brasil, indica-se um fluxograma composto por tratamento secundário seguido de desinfecção direta para usos restritos; e secundário seguido de filtração terciária, além de desinfecção para usos irrestritos (INTERÁGUAS, 2018).

\subsection{Padrões de reúso para usos urbanos}

Seguindo a metodologia de exposição anterior, apresentam-se na Tabela 8 os padrões de contaminação fecal (Coliformes termotolerantes no Brasil e Escherichia coli em Portugal) para usos em ambientes urbanos.

Tabela 8: Padrões de contaminação fecal para o reúso de água para ambientes urbanos no Brasil e em Portugal

\begin{tabular}{lcc}
\hline \multicolumn{1}{c}{ Classe de rega/irrigação } & Brasil & Portugal \\
\cline { 2 - 3 } & $\begin{array}{c}\text { Coliformes } \\
\text { termotolerantes } \\
\text { NMP/100mL }\end{array}$ & $\begin{array}{c}\text { E. Coli } \\
\text { UFC/100 mL }\end{array}$ \\
\hline Recreativo e enquadramento paisagístico & - & 10 \\
Lavagem de ruas & 10 & $-(1)$ \\
Combate a incêndio & $10^{3}$ & 10 \\
Descarga (autoclismo) de vaso sanitário & 10 & 10 \\
Lavagem de veículos & $10^{3}$ & 10 \\
Arrefecimento & - & 200 \\
Desobstrução de galerias de esgotos e águas pluviais & 10 & - \\
Construção civil & 10 & - \\
Lagoas urbanas, manutenção de wetlands e aumento da & $10^{3}$ & - \\
disponibilidade hídrica para fins ambientais & & \\
\hline
\end{tabular}

Fonte: INTERÁGUAS (2018); Portugal (2019).

Nota: ${ }^{(1)} \mathrm{O}$ documento regulador português assume a lavagem de ruas como um uso possível para água de reúso. No entanto, não define padrão para indicadores de contaminação fecal.

Geralmente, os usos determinados para a água de reuso em ambientes urbanos são distinguidos em potáveis e não potáveis. Os usos potáveis podem dividir-se em direto ou indireto. Segundo Angelakis et al. (2018), o uso potável direto é definido quando o efluente de uma estação de tratamento avançada é encaminhado diretamente à uma Estação de Tratamento de Água (ETA) ou até mesmo, diretamente à rede de distribuição de água de abastecimento; o uso potável indireto é definido quando o efluente de uma estação de tratamento avançada é diluído no manancial superficial à montante da captação para abastecimento público ou serve como recarga de aquífero subterrâneo (espalhamento ou injeção). Ressalta-se ainda, que o reuso indireto não planejado, conhecido por "de facto", ocorre de maneira indiscriminada, com o lançamento de efluentes brutos ou tratados à montante da captação de água para abastecimento público.

O reúso potável planejado, direto e indireto, apesar de não estar no escopo dos documentos legais do Brasil e de Portugal, é adotado em vária regiões do mundo, inclusivamente com regulação 
específica para esse fim (MUKHERJEE e JNESEN, 2020; HARTLEY; TORTAJADA $\mathrm{e}$ BISWAS, 2019; VAN RENSBURG, 2016; LAHNSTEINER; VAN RENSBURG e ESTERHUIZEN, 2018; KHAN e ANDERSON, 2018). Os usos urbanos não potáveis, como os indicados nos documentos reguladores tanto do Brasil como de Portugal, apresentam maior simplicidade de manejo e gestão, além de poderem conferir menor risco de contaminação.

Asano (2007) define para a categoria de usos urbanos não potáveis, os seguintes: proteção contra incêndio, ar condicionado e descarga de vaso sanitário. Os usos para irrigação de jardins, campos de desporto, parques e demais áreas urbanas, são definidos como usos relacionados à irrigação paisagística. De maneira complementar, Chhipi-Shrestha, Hewage e Sadiq (2017) elencaram aplicações potenciais para a água de reúso para fins urbanos não potáveis e que estão diretamente ligados à qualidade alcançada e às necessidades de cada região: i) irrigação de gramado e jardins; ii) irrigação de parques públicos; iii) irrigação de campos de golfe; iv) descarga de vaso sanitário; v) lavagem de veículos; vi) máquina de lavar roupa; e vii) combate a incêndio. Angelakis et al. (2018), ainda indicam a lavagem de rua como uma possibilidade para 0 reúso de água, dentre as demais já mencionadas. Há ainda que se considerar a possibilidade do reúso descentralizado, onde o produtor da água de reúso é o próprio gerador ou ambos (produtor e gerador) se encontram mais próximos. No Brasil, a NBR 16.783:2019 (ABNT, 2019) aborda parâmetros para fontes alternativas de água em edificações, mas não está no contexto dessa análise. Os documentos reguladores do Brasil e de Portugal analisados nesse trabalho, não consideram o reúso de água descentralizado, apesar de o documento de Portugal indicar a possiblidade do uso local pela própria EG.

Conforme se depreende da informação contida na Tabela 8 , as aplicações de reúso urbano não potável indicadas anteriormente por diversos autores, são contempladas em ambos os documentos reguladores estudados. Salienta-se, ainda, o fato dos padrões de reúso para construção civil e desobstrução de tubulações de águas residuais estarem contemplados, exclusivamente, no documento regulador brasileiro.

Para o uso em limpeza de galerias de esgotamento sanitário e de águas pluviais urbanas, o documento regulador brasileiro é bastante restritivo, sugerindo um risco elevado de contaminação de usuários e operadores. Essa atividade é relevante para o Brasil, considerando que as tubulações e condutos se apresentam constantemente assoreados e entupidos, devido à interferência tanto de esgotos em condutos de drenagem pluvial como de água de chuva em tubulações de esgoto, mesmo o país adotando, majoritariamente, o sistema separador para condução dos esgotos. Volschan (2020) ressalta que o sistema de esgotamento sanitário adotado no Brasil é do tipo separador, por uma questão técnica que leva em consideração o regime típico de chuvas de um clima tropical. Entretanto, o mesmo autor destaca as deficiências operacionais e de gerenciamento que influenciam o desempenho de sistemas separadores com volumes inadequados de águas pluviais em períodos de chuva. De acordo com Dias e Rosso (2011), a interconexão entre os sistemas de esgoto sanitário e a drenagem pluvial ocorre de várias formas, desde a ligação das instalações prediais de esgoto sanitário nas instalações de águas pluviais internas dos imóveis e loteamentos, até ao lançamento final de trechos das galerias de águas pluviais na rede de esgoto sanitário. Porém, o fato desses sistemas serem muitas vezes concebidos e geridos como sistemas separadores, implica uma elevada complexidade operacional. Nesse sentido, há necessidade de uma intensa atividade de desobstrução dessas galerias, frequentemente assoreadas e entupidas, podendo esta operação ser realizada com água de reúso.

No caso da construção civil, o documento regulador brasileiro sugere que a água de reúso não seja adotada para fins estruturais (INTERÁGUAS, 2018). Há diferentes atividades na construção civil onde se utilizam grandes volumes de água, que podem ser supridas com água de reúso, como por exemplo: abaixamento de poeiras, equipamento de corte e perfuração, cura de concreto, dentre outros. De maneira complementar, pesquisas conduzidas sobre a produção de concreto não estrutural, com uma combinação entre água potável e água de reúso em diferentes proporções reforçam o potencial de adoção da água de reúso nessa atividade, sendo relevante, neste caso, o conhecimento das concentrações de elementos alcalinos para prevenir reações com o agregado (AL-GHUSAIN e TERRO e 2003; ASADOLLAHFARDI et al., 2016; DUARTE et al., 2019). 
Os usos para lavagem de veículos e para combate a incêndio apresentam abordagens distintas entre os dois países. Em Portugal, o risco associado à prática dessas duas tipologias de reúso urbano é considerado elevado e o seu documento regulador determina um padrão para $E$. Coli de até $10 \mathrm{UFC} / 100 \mathrm{~mL}$. Já no caso do Brasil, os mesmos usos são considerados de menor risco dentre os demais, estabelecendo-se um valor para coliformes termotolerantes de até 1000 NMP/100mL. Kotouc e Krocova (2020) indicam que o problema relacionado com estes usos está associado ao acúmulo dessas águas a longo prazo, ao fenômeno de conexão cruzada, e à elevada probabilidade de contato da população com a água de reúso, levando ao maior risco de contaminação.

No caso da lavagem de ruas, o documento regulador do Brasil demonstra grande preocupação com o risco de contaminação, pois define um critério demasiado restritivo (Coliformes termotolerantes < $10 \mathrm{NMP} / 100 \mathrm{~mL}$ ). Essa prática assume grande importância para limpeza de ambientes externos após feiras livres e eventos populares no Brasil. Segundo Silva Jr. et al. (2019), a maioria das prestadoras de serviços de água e esgoto na região Sudeste do país que adotam a prática de reúso, a fazem para fins de limpeza de ruas. Por outro lado, o documento regulador português apresenta padrões para este uso, porém não estabelece valores para indicadores de contaminação fecal.

Para ambos os documentos reguladores analisados, a descarga de vaso sanitário representa risco elevado. No âmbito do uso doméstico, o vaso sanitário é o maior consumidor de água, representando aproximadamente $40 \%$ do consumo total (SOUZA et al. 2016). Em geral, a água de reúso destinada a esta utilização é um tipo de uso urbano não potável descentralizado, onde muitas vezes se adota a água cinza tratada in loco (GONÇALVES; SIMÕES e WANKE, 2010; LAZAROVA; HILLS e BIRKS, 2003). Porém, Lazarova; Hills e Birks (2003) indicam sistemas à escala municipal em operação no Japão e nos Estados Unidos da América em que os padrões microbiológicos apresentam elevada variação.

Embora não haja uma correspondência direta entre os padrões previstos em Portugal para os usos recreativos e enquadramento paisagístico, e no Brasil, para os usos em lagoas urbanas, manutenção de wetlands e aumento da disponibilidade hídrica para fins ambientais, podem assumir-se objetivos comuns nos dois documentos reguladores para estes usos, com a imposição de indicadores microbiológicos. Em decorrência de o documento regulador português abranger nesse uso a possibilidade de recreação, - seu padrão de contaminação fecal é mais restritivo (10 UFC/100mL para E. Coli) do que o brasileiro $\left(10^{3} \mathrm{NMP} / 100 \mathrm{~mL}\right.$ para coliforme termotolerantes).

\section{CONCLUSÃO}

No presente trabalho foi realizada uma análise comparativa entre os aspectos reguladores relacionados com o reúso de água no Brasil e em Portugal, diante dos cenários de gestão de recursos hídricos e de saneamento ambiental dos dois países. Nesses cenários, como seria de esperar, foram observadas significativas diferenças entre Brasil e Portugal, considerando os índices de atendimento em relação ao abastecimento de água e ao esgotamento sanitário, além da disponibilidade hídrica. Apesar das diferenças, as taxas de reúso de água em relação ao esgoto total tratado são similares no Brasil $(1,5 \%)$ e em Portugal $(1,2 \%)$. Pese embora o índice de tratamento de esgotos no Brasil (46\%) ser inferior ao de Portugal (85\%), o volume anual de água de reúso no Brasil $\left(63 \times 10^{6} \mathrm{~m}^{3} / \mathrm{ano}\right)$ é, em valores absolutos, substancialmente superior ao de Portugal $\left(8,5 \times 10^{6} \mathrm{~m}^{3} / \mathrm{ano}\right)$, que decorre da óbvia observação das respetivas magnitudes populacionais.

O documento regulador do Brasil não tem caráter de lei e, portanto, não é mandatório. No entanto, apresenta padrões para o reúso agrícola, urbano, ambiental, industrial e aquícola, além de diretrizes para a sua aplicação, considerando ainda: i) indicação de tecnologias de tratamento de esgotos para alcance da qualidade desejada; ii) aspectos de licenciamento; e iii) seguro contra incidentes.

Em Portugal, o documento regulador, por se tratar de um documento com força legal, apresenta-se bem estruturado e é acompanhado por um guia de reutilização publicado pela APA, com o objetivo de institucionalizar a prática e todos os seus instrumentos. A ferramenta de gestão de risco apresenta-se, de forma destacada, no enquadramento legal de Portugal, além dos mecanismos para o processo de licenciamento, o seguro contra incidentes e a obrigatoriedade de depósito de caução para pagamento de 
indemnizações em casos de eventualidades. Em relação à gestão do risco, o guia de reutilização, apresenta instruções e exemplos de aplicação prática para o desenvolvimento da metodologia de análise do risco (quantitativa, semiquantitativa ou qualitativa).

Em relação aos padrões de qualidade de água de reúso para os diferentes fins, o Brasil tende a ser mais flexível do que Portugal, de forma a incentivar a generalização da prática de reúso nas situações onde couber. Considera-se que essa experiência adquirida poderá proporcionar uma maior exigência nos padrões estabelecidos, futuramente.

A análise comparativa, objecto do presente trabalho, constitui um subsídio para realçar os esforços desenvolvidos, tanto em Portugal como no Brasil, na estruturação de mecanismos legais para a utilização racional e em segurança de águas residuais tratadas. Os fenómenos dramáticos de secas prolongadas, intensificados pelos efeitos das alterações climáticas e afetando largas regiões do Brasil e Portugal, aconselham a institucionalização e aplicação de instrumentos legais que contemplem a generalização do reúso de água. Para além de se fomentar a circularidade do ciclo urbano da água, promovem-se, assim, políticas ativas de segurança hídrica em cenários de desenvolvimento sustentável.

\section{AGRADECIMENTOS}

Os autores agradecem à Universidades do Minho pelo acolhimento do trabalho de pós doutoramento e à Universidade Estadual do Rio de Janeiro pela liberação da pesquisadora, apoios fundamentais para a realização deste estudo, possibilitando 0 desenvolvimento de um melhor conhecimento dos enquadramentos legais instituídos no Brasil e em Portugal, relativos ao reúso de água.

\section{REFERÊNCIAS}

AL-LAHHAM, O.; EL-ASSI, N.M.; FAYYAD, M. Impact of treated wastewater irrigation on quality attributes and contamination of tomato fruit. Agricultural Water Management, v. 61, p. 51-62, 2003.

AL-GHUSAIN, I.; TERRO, M. Use of treated wastewater for concrete mixing in Kuwait. Kuwait journal of science and engineering, v. 30, p. 213-228; 2003.
ANA - AGÊNCIA NACIONAL DE ÁGUAS. Atlas esgotos: despoluição de bacias hidrográficas, p. 88. Brasília: ANA, 2017.

ANA - AGÊNCIA NACIONAL DE ÁGUAS. Conjuntura dos recursos hídricos no Brasil: Regiões hidrográficas brasileiras. Brasília: ANA, 2018.

ANA - AGÊNCIA NACIONAL DE ÁGUAS. Conjuntura dos recursos hídricos no Brasil 2019: informe anual, p. 100. Brasília: ANA, 2019.

ANGELAKIS, A.N.; ASANO, T.; BAHRI, A.; JIMENEZ, B.E.; TCHOBANOGLOUS, G. Water reuse: from ancient to modern times and the future. Frontiers in environmental science, v. 6, n. 26, 2018.

APA - AGÊNCIA PORTUGUESA DO AMBIENTE. Guia para reutilização de água - usos não potáveis. Lisboa: APA, 2019.

ARAUJO, B.M.; SANTOS, A.S.P.; LIMA, M.A.M.; SOARES, S.R.A.; PERDIGÃO, C.A.; MELO, M.C. Avaliação do potencial de reuso de efluentes de ETE em áreas irrigadas da bacia hidrográfica Piancó-PiranhasAçu com vistas a universalização. Revista Augustus, v. 24, n. 49, p. 179-191, 2019.

ASADOLLAHFARDI, G.; DELNAVAZ, M.; RASHNOIEE, V.; GHONABADI, N. Used of treat domestic wastewater before chlorination to produce and cure concrete. Construction and Building Materials, v. 105, p. 253261, 2016.

ASANO, T.; BURTON, F.; LEVERENZ, H. Water reuse: issues, technologies and applications. New York: Metcalf \& Eddy AECON, eds. McGraw Hill, 2007.

ASSOCIAÇÃO BRASILEIRA DE NORMAS TÉCNICAS (ABNT). Norma Brasileira NBR 16783/2019 - Uso de fontes alternativas não potáveis em edificações. Rio de Janeiro, RJ, 2019.

BEAUDEQUIN, D.; HARDEN, F.; ROIKO, A.; STRATTON, H.; LEMCKERT, C.; MENGERSEN, K. Modeling microbial health risk of wastewater reuse: $A$ systems perspective. Environmental International, v. 84, p. 131-141, 2015.

BRASIL. Ministério do Desenvolvimento Regional. Secretaria Nacional de Saneamento - SNS. SISTEMA NACIONAL DE INFORMAÇÕES SOBRE SANEAMENTO: $24^{\circ}$ Diagnóstico dos serviços de água e esgoto - 2018, p. 180. Brasília, 2019.

CHHIPI-SHRESTHA, G.; HEWAGE, K.; SADIQ, R. Microbial quality of reclaimed water for urban reuses: Probabilistic risk-based investigation and 
recommendations. Science of the Total Environment, v. 576 , p. $738-751,2017$.

CUNHA, A.P.M.A.; ALVALA, R.C.S.; NOBRE, C.A.; CARVALHO, M.A. Monitoring vegetative drought dynamics in the Brazilian Semiarid Region. Agric. For Meteorol, v. 214, p. 494-505. 2015.

DIAS, A.P.; ROSSO, T.C.A. Análise dos elementos atípicos do sistema de esgoto - separador absoluto - na cidade do Rio de Janeiro. Engevista, v. 13, n. 3, p. 177192, 2011.

DUARTE, N.C.; AMARAL, A.E.S.; GOMES, B.G.L.A; SIQUEIRA, G.H.; TONETTI, A.L. Water reuse in the production of non-reinforce concrete elements: an alternative for decentralized wastewater management. Journal of water, sanitation and hygiene for development, v. 9, n. 3, p. 596-600, 2019.

ERSAR - ENTIDADE REGULADORA DOS SERVIÇOS DE ÁGUAS E RESÍDUOS. Relatório anual dos serviços de águas e resíduos em Portugal (RASARP) 2019 - Vol. 1: Caracterização do setor de águas e resíduos. Lisboa: ERSAR, 2019.

FERREIRA, P.S.F.; MOTTA, P.C.; SOUZA, T.C.; SILVA, T.P.; OLIVEIRA, J.F.; SANTOS, A.S.P. Avaliação preliminar dos efeitos da ineficiência dos serviços de saneamento na saúde pública brasileira. Revista internacional de ciências, v. 6, n. 02, p. 214-229, 2016.

GONÇALVES, R.F.; SIMÕES, G.M.S.; WANKE, R. Reúso de água cinzas em edificações urbanas: estudo de caso em Vitória (ES) e Macaé (RJ). Revista AIDIS, v. 3, n. 1, 2010.

HARRIS-LOVETT, S.R.; BINZ, C.; SEDLAK, D.; KIPARSKY, M.; TRUFFER, B. Beyond user acceptance: a legitimacy framework for potable water reuse in California. Environmental Science and Technology, v. 49, n. 13, p. 7552-7561, 2015.

HARTLEY, K.; TORTAJADA, C.; BISWAS, A.K. A forma model concerning policy strategies to build public acceptance of potable water reuse. Journal of environmental management, v. 250, 2019.

HELLER, L.; COLOSIMO, E.A.; ANTUNES, C.M.F. Environmental sanitation conditions and health impacts: a case control study. Revista da sociedade brasileira de medicina tropical, v. 36, n. 1, 2003.

IBGE - INSTITUTO BRASILEIRO DE GEOGRAFIA E ESTATÍSTICA. Disponível em: https://www.ibge.gov.br/geociencias/organizacao-doterritorio/estrutura-territorial/15761-areas-dosmunicipios.html?=\&t=0-que-e. Acessado em: 04 de abr. 2020a.
IBGE - INSTITUTO BRASILEIRO DE GEOGRAFIA E ESTATÍSTICA. Projeções e estimativas da população do Brasil e das unidades da federação. Disponível em: https://www.ibge.gov.br/apps/populacao/projecao/. Acessado em: 27 de mar. 2020b.

INTERÁGUAS

PROGRAMA

DE

DESENVOLVIMENTO DO SETOR ÁGUAS.

Elaboração de proposta de plano de ações para instituir uma política de reúso de efluente sanitário tratado no Brasil. Produto III - Critérios de qualidade de água. Brasília: MMA/MCidades, 2018.

KHAN, S.J.; ANDERSON, R. Potable reuse: experiences in Australia. Environmental Science and Health, v. 2, p. 55-60, 2018.

KOTOUC, D.; KROCOVA, S. Utilization of recycled water as an alternative source of water used for firefighting purposes by fire brigades in the Czech Republic. In: IOP Conference Series: Earth and Environmental Science. Advances in Environmental Engineering, v.444, 2017. Ostrava, Czech Republic. Published in $2020 . \quad$ Disponível em: https://iopscience.iop.org/article/10.1088/17551315/444/1/012029. Acesso em: junho de 2020.

LAHNSTEINER, J.; VAN RENSBURG, P.; ESTERHUIZEN, J. Direct potable reuse - a feasible water management option. Water reuse and desalination, v. 8, n. 1, 2018.

LAZAROVA, V.; HILLS, S.; BIRKS, R. Using recycled water non-potable, urban uses: a review with particular reference to toilet flushing. Water science and technology, v. 3, n. 4, p. 69-77, 2003.

LOUREIRO, D.; AMADO, C.; MARTINS, A.; VITORINO, D.; MAMADE, A.; COELHO, S.T. Water distribution systems flow monitoring and anomalous event detection: a practical approach. Urban water journal, v. 13, n. 3, p. 242-252, 2016.

MARIN, P., TAL, S., YERES, J., KLAS, R. Water Management in Israel: Key Innovations and Lessons Learned for Water Scarce Countries. Banco Mundial, Washington, DC. 2017.

MENG, F.; FU, G.; BUTLER, D. Water Quality permitting: from end-of-pipe to operational strategies. Water research, v. 101, p. 114-126, 2016.

MUKHERJEE, M.; JENSEN, O. A comparative analysis of the development of regulation and technology uptake in the US and Australia. Safety Science, v. 121, p. 5-14, 2020.

MUTIKANGA, H.E.; SHARMA, S.; VAIRAVAMOORTHY, $\mathrm{K}$. Water loss management in developing countries: 
challenges and prospects. Journal American Water Works Association, v. 101, n. 12, p. 57-68, 2009.

OVIEDO-OCAÑA, E.R.; DOMINGUEZ, I.C.; CELIS, J.; BLANCO, L.C.; COTES, I.; WARD, S.; KAPELAN, Z. Water-loss management under data scarcity: case study in a small municipality in a developing country. Journal of water resource planning and management, v. 146, n. 3,2020 .

PEDRERO, F.; KALAVROUZIOTIS, I.; ALARCÓN, J.J.; KOUKOULAKIS, P.; ASANO, T. Use of treated municipal wastewater in irrigated agriculture - Review of some practices in Spain and Greece. Agricultural Water Management, v. 97, p. 1233-1241, 2010.

PORDATA - Base de Dados Portugal Contemporâneo. Disponível: https://www.pordata.pt/Portugal. Acesso em: 27 de mar. 2020.

PORTUGAL. Decreto Lei $N^{\circ} 119$ de 21 de agosto de 2019. Estabelece o regime jurídico de produção de água para reutilização, obtida a partir do tratamento de águas residuais, bem como da sua utilização. Lisboa, 2019.

RICART, S.; RICO, A.M. Assessing technical and social driving factors of water reuse in agriculture: a review on risks, regulation and yuck factor. Agricultural water management, v. 217, n. 20, p. 426-439, 2019.

ROCHA, R.E.M.; PIMENTEL, M.S.; ZAGO, V.C.P. Avaliação de biossólido de águas servidas domiciliares como adubo em couve. Pesquisa Agropecuária Brasileira, v. 38, n. 12, p. 1435-1441, 2003.

ROCK, C.M.; BRASSIL, N.; DERY, J.L.; CARR, D.; MCLAIN, J.E.; BRIGHT, K.R.; GERBA, C.P. Review of water quality criteria for water reuse and risk-based implications for irrigated produce safety rule. Environmental Research, v. 172, p. 616-619, 2019.

SALGOT, M.; HUERTAS, E.; WEBER, S.; DOTT, W.; HOLLENDER, J. Wastewater reuse and risk: definition of key objectives. Desalination, v. 187, p. 29-40, 2006.

SANTOS, R.M.B.; FERNANDES, L.F.S.; CORTES, R.M.V.; PACHECO, F.A.L. Development of a hydrologic and water allocation model to assess water availability in the Sabor river basin (Portugal). International Journal of environmental research and public health, v. 16, n. 2419, 2019.

SANTOS, S.S.; SOARES, A.A.; MATOS, A.T.; MANTOVANI, E.C.; BATISTA, R.O.; MELO, J.C.
Contaminação microbiológica de do solo e dos frutos de cafeeiros fertirrigados com esgoto sanitário. Engenharia na Agricultura, v. 14, n. 1, p. 16-22, 2006.

SATO, T.; QADIR, M.; YAMAMOTO, S.; ENDO, T.; ZAHOOR, A. Global, regional, and country level need for data on wastewater generation, treatment, and use. Agricultural water management, v. 130, p. 1-13, 2013. SOUZA, J.F.; NETO, M.R.F.; SOUZA, M.A.S.; VENEU, D.M. Aproveitamento de água de chuva para usos não potáveis na Universidade Severino Souza. Revista Eletrônica Teccen, v. 09, n. 1, p. 36-46. 2016.

SILVA Jr.; L.C.; ARAUJO, B.M.; SANTOS, A.S.P.; OBRACZKA, M. BOTTREL, S.E.C. Panorama do reúso de água das estações de tratamento de esgotos da região Sudeste. In: $30^{\circ}$ Congresso Brasileiro de Engenharia Ambiental e Sanitária. Natal/RN, 2019. Anais. Rio de Janeiro, ABES. 2019.

TSAGARAKIS, K.P.; MENEGAKI, A.N.; SIARAPI, K.; ZACHAROPOULOU, F. Safe alerts reduce willingness to visit park irrigated whit recycled water. Journal of risk research, v. 16, n. 2, 2013.

TZANAKAKIS, V.A.; PARANYCHIANAKIS, N.V.; LONDRA, P.A.; ANGELAKIS, A.N. Effluent application to the land: Changes in soil proprieties and treatment potential. Ecological Engineering, v. 37, n. 11, p. 17571764. 2011.

UNPD - UNITED NATIONS DEVELOPMENT PROGRAMME. Human Development Report 2019. Beyond income, beyond averages, beyond today: Inequalities in human development in the $21^{\text {st }}$ century. 366p. New York-USA: UNPD, 2019.

VAN RENSBURG, P. Overcoming global water reuse barriers: the Windhoek experience. International Journal of water Resources Development, v. 3, n. 4, 2016.

VIEIRA, J.M.P. A Strategic Approach for Water Safety Plans Implementation in Portugal. Journal of Water and Health, IWA Publishing, 09.1, p. 107-116, 2011.

VIEIRA, J.M.P. Água e Saúde Pública. Lisboa: Editora Silabo, 2018.

VOLASCHAN, I. The challenge of dry-weather sewage intakes as a sustainable strategy to develop urban sanitation in the tropics. Water Practice \& Technology, v. 15 , n. 1 , p. $38-47.2020$. 